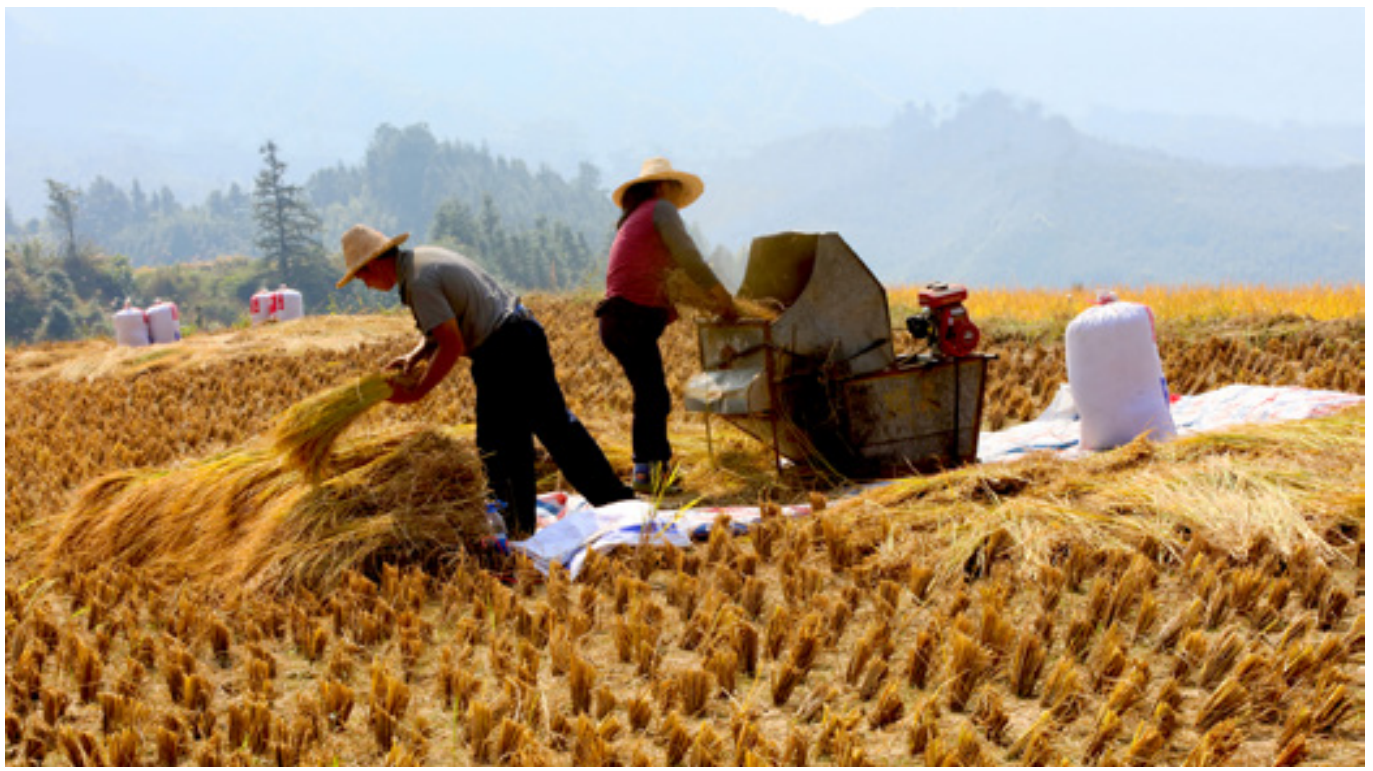

\section{Researching China Through Translation and Presentation}

Wenjing JIANG

To present a research project as understandable, inoffensive, and interesting to people in the field involves both politics and artfulness. Researchers, the researched, and potential collaborators together constitute the politics of fieldwork, at the centre of which are ongoing processes to establish expectations of possible benefits or conflicts of interests. The multidimensional politics on the ground remind us to consciously and continually seek appropriate translation and presentation of our research and position while conducting fieldwork in China.
Qingyuan Guangdong

farmers at work. PC: @peteropaliu (Flickr.com).

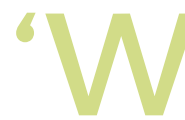

hat is your research about? What do you want to know, and how?' We are trained in academia to address these questions in a thousand different ways, depending on who is asking. We tend to think that, with the skills to speak to colleagues, reviewers, funders, and policymakers, we can deal with the same questions during fieldwork with ease. Unfortunately, this is never the case. To present a research project as understandable, inoffensive, and interesting to people in the field involves both politics and artfulness, yet we rarely discuss how. Drawing on my experience in rural Sichuan, I show how researchers, the researched, and potential collaborators together constitute the 
politics of fieldwork, at the centre of which are ongoing processes to establish expectations of possible benefits or conflicts of interests. With a snapshot of this politics on the ground, I will reflect on how researchers encounter with the so-called 'politically-sensitive' issues in the field and how such encounters intertwine with the ongoing efforts to seek appropriate translation and presentation of research projects during fieldwork.

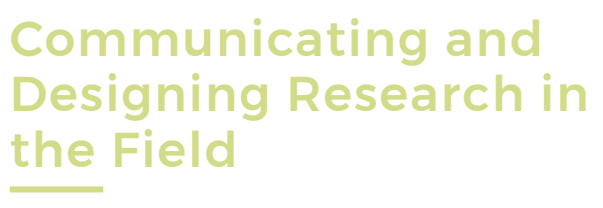

Establishing contacts with China-based collaborators remains a crucial step for successful entry into the field (Thunø 2006). Local scholars, officials, cadres, and other key informants-with their ability to provide access to certain sites or networks-can all act as gatekeepers. To request support from them involves learning in practice how to properly introduce research ideas and deal with multiple dimensions of politics. It was this learning process that helped me refine my research scope and design.

While researching the post-Wenchuan Earthquake recovery in Sichuan for my master's thesis, I became interested in the transfer of rural land use rights, which is the lens I have used to look into changes in property, production, and broader social relations in $\mathrm{my}$ doctoral dissertation. Given the multiple types of rural land (Zhang and $\mathrm{Wu} 2017,99-100$ ) and the spectrum of land transfer practices, the foremost task in the first phase of my research was to decide which specific type(s) of land to focus on and which research site(s) could be appropriate. My initial attempts to seek help from local scholars, however, resulted in complete failure. With a full page of research questions from my dissertation proposal in my head, I excelled at boring my contacts with non-stop lectures introducing my topic.
As a result, I decided to shift my strategy and keep everything brief. I used the one-sentence description in the recruitment script approved by the Institutional Review Board, which states that my study focuses on land transfers and agrarian transformation. How to explain what I mean by 'agrarian transformation' became the next challenge. While the Chinese character nong (农) captures the hybrid meaning of the English word 'agrarian', it must be combined with other characters to constitute a useable word. Depending on the context, 'agrarian' can be translated into different words in Chinesefor instance, nongye (农业, 'agricultural'), nong zheng (农政, 'agricultural and political'), and sometimes tudi (土地, 'land')-each indicating a distinct scholarship and certain presumed positionality attached to it. For instance, nong zheng comes directly from the classic agrarian political economy, but the word is rarely used or understood outside of the small research community. Adopting any of these existing translations, or even the indigenous term san nong (三农, 'three rural issues'), risks creating linguistic and positional barriers between potential collaborators and myself. Eventually, I found nongcun zhuanxing (农村转型, 'rural transformation') the safest to use and the best understood, although questions on my theories and methods often followed.

My project is deeply informed by Marxist political economy, but referring to this label in the Chinese context would only make things tricky. China's agrarian reform has always been a battlefront between Marxists, neoclassical economists, and the new institutionalists, who receive disparate trainings and serve different functions. Teaching and research responsibilities of Marxist scholars in China are often closely related to political ideology. To make it less political, I would prefer to introduce myself as a political economist in general, rather than a Marxist, terms. Yet the economists actively engaged with policymaking tend to think of 'political economy' as a small body of literature they are familiar with-e.g., institutional political economy-and thus find my work far from innovative and do not think 
it is worth their time to learn more. To avoid the Left-Right politics, I have tried to use the disciplines of human geography or agricultural geography as a cover, which just made people more confused about my training and unsure of how they could help me. In mainland China, geography at the university level is a science discipline, while pre-college geography education belongs to the social sciences and humanities track. Not knowing how they should treat me, as a student in sciences or social sciences, non-geographers often had a hard time figuring out what I needed.

In the end, I learned to present my project as qualitative research (定性研究) on rural land transfers (土地流转) using data primarily from interviews (访谈). I did not like this description at all. It did tell (at least part of) what I intended to do, but without revealing my real passion-to answer the complex yet interesting questions about China's agrarian change using multiple sources of information-I felt detached from the expression. Nevertheless, it worked. It was only after hearing I use qualitative approaches that an agricultural economist I met breathed a sigh of relief, mentioned the quantitative household survey conducted by his group, and suggested future collaborations. Shared interests do create topics to collaborate on, but too much overlap of skill or data coverage may kill potential trust due to perceived competition. Sometimes, local scholars must feel that you are roughly on the same side but not competing with them before they will offer help.

Local scholars gave unsolicited advice on what I should study. Some suggested researching the transfer of construction rights of rural residential land (宅基地) rather than that of agricultural land use rights, even though what I asked for was access to specific cases. Since the former is often associated with large amounts of money and thus complex interests and politics at township and county levels, I realised the difficulty of obtaining support from local gatekeepers. Moreover, back in 2016, issues around agricultural land attracted much less scholarly attention compared to those on rural residential land. I thus decided to focus on agricultural land instead. My decision ended up ruining some promising professional support. Some scholars even chided me for choosing to connect land transfers to agricultural restructuring, arguing that agricultural land transfers were nothing new.

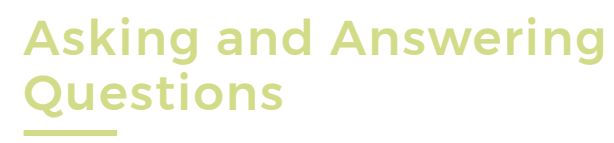

Fieldwork after entry and access does not become easier. Rather, it requires higher sensitivity to local politics and more finely tuned skills to handle a variety of situations. In Chinese, both 'politics' and 'political' are referred to as zhengzhi (政治), which means issues related to the people and events in the hierarchical governing system, often at higher levels. Thus 'to criticise the Chinese government is risky', as the US-based Institutional Review Board kept reminding me. Yet, what accounts as political varies from one context to another. Political economists and theorists would highlight the political part in almost everything. In rural China, the giant thing called the 'State' disappears and is often replaced by local and interpersonal politics. This happens particularly when the abstract 'political' reveals itself as concrete politics through the 'choice between conflicting alternatives' (Mouffe 2005, 8-10), for example when local people decide whether to participate in my research.

Those who agree to talk may have diverse incentives underpinning their choice. In my experience, when introduced to me by someone with a higher status-such as a local official or cadre-informants do not deny a request for interviews, but might express their reluctance to share what they know in subtle ways. Also, there are villagers chosen to serve as 'typical examples' (典型) and frequently introduced to visitors by local cadres. These 'professional interviewees', as I call them, are highly skilled 
at judging what roles they should play-as policy beneficiaries, hardworking agricultural practitioners, or exploited peasants-and perform accordingly to meet the expectations of officials or researchers. Some more 'unprofessional interviewees' would complain about being taught what to say by their village leaders when the latter are absent during interviews. Some would make a million other complaints hoping that I, with the capacity to write things down, could speak on their behalf to policymakers or people at higher levels to reverse their disadvantageous situations. Some would share all their miseries since they had never met anyone else as patient as I was who would sit down for hours listening to their stories. Others were simply curious about what I do and reached out to look for information so that they could have something to say when they discuss me with their neighbours.

In short, the various incentives behind politeness and eagerness may result in exaggerated statements and inaccurate information. Before piecing together all evidence and telling the stories, therefore, one has to validate what is said by observing what people do and why. One strategy I adopted was to make my empirical questions more tangible. Instead of asking people how they think about something or why they do certain things (always the most difficult questions to answer), I learned to ask 'what questions'-e.g. questions about their farming techniques, inputs, yields, and profits. As most villagers expressed their interest in the geography of crops and farming practices, I also shared my knowledge of agricultural practices in Northeast China where I grew up and sometimes other parts of the world, together with my own confusions about what I observed locally. Personal reflections on politics, policies, and social meanings come up naturally in a good conversation. When they do, we as researchers must follow informants quickly in shifting from a depoliticised conversation to a highly politicised one, for example by comparing what they get and what their neighbours get in the emerging land transfer practices.

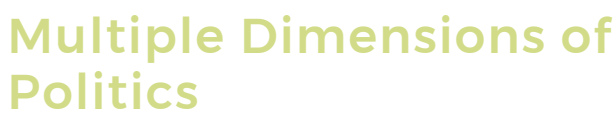

Field research in China involves multiple dimensions of politics. As I have argued, researchers should consciously and continually seek appropriate translation and presentation of the research projects and researchers' position while conducting fieldwork in China. In addition to the shifting languages between Chinese and English, between standard Mandarin and local dialects, and between official and unofficial discourses (Thøgersen 2006)-more attention to the nuanced differences between abstract concepts and empirical terms, and between politicising and depoliticising the same questions will facilitate the search for shared interests, values, and experiences. This will eventually open up opportunities for genuine discussions that may otherwise be impossible. 